\title{
Numerical analysis of the stability of inhomogeneous slopes considering partially saturated conditions
}

\author{
Patrick P. Pichler ${ }^{1, a}$ and Helmut F. Schweiger ${ }^{1}$ \\ ${ }^{1}$ Graz University of Technology, Institute of Soil Mechanics and Foundation Engineering, Computational Geotechnics Group, 8010 Graz, Austria
}

\begin{abstract}
It is well accepted that rainfall could play a significant role in instability of slopes. The main objective of the presented study is to quantify the influence of varying characteristics of water flow, its associated changes of pore-water pressures and shear strength on the stability of simplified, but inhomogeneous, slope geometries. The commonly used van Genuchten model was used to describe the Soil Water Characteristic Curve (SWCC) mathematically. In the context of this study, the influence of different hydraulic behaviour of soil layers, i.e. different SWCC, on the factor of safety (FoS) is evaluated by means of fully coupled flow-deformation analyses employing the finite element method. To quantify the slopes' factor of safety during rainfall events after specified times of infiltration or evaporation, the strength reduction method was applied. In addition to various combinations of soil layers, the influence of a water bearing high permeable soil layer between two less permeable soil layers, a situation which is often encountered in practice, on the factor of safety has been investigated.
\end{abstract}

\section{Introduction}

Numerous researchers discussed the most significant factors which control the instability of homogeneous soil slopes under rainfall infiltration [e.g. 1-2]. Basically, the initial FoS of a slope with given soil properties is controlled by its geometry, the depth of the groundwater table and the corresponding initial matric suction-profile in the unsaturated zone which is defined by the soilwater-characteristic curve (SWCC). The soil properties and the rainfall intensity have a greater impact on the factor of safety than the slope geometry and initial water table. The position of the initial groundwater level and the soil layers with different hydraulic behaviour defines the initial suction- and saturation-profile throughout the slope. The hydraulic characteristics of the soil such as saturation, which determines the relative permeability, and the intensity and duration of rainfall defines the actual infiltration rate into the slope. Additionally, the influence of different variations in geometry and impacts of various rainfall scenarios on the development of the FoS with time were evaluated.

The main objective of this study is to determine worst-case scenarios due to various combinations of different permeable soil layers under predefined hydraulic conditions. To estimate the FoS of the slope after predefined time periods of a rainfall event the wellknown strength reduction technique was applied. The analyses were performed employing two-dimensional finite element models utilizing the code PLAXIS $2 D$ [3].

\section{Geometry and boundary conditions}

The geometry of the slope and its boundary conditions are illustrated in figures 1 and 2. The height of the slope is $10 \mathrm{~m}$ and the slope angle $\alpha$ is $26.56^{\circ}$ (horizontal to vertical is $2: 1$ ). The initial groundwater level was assumed to be inclined with the same angle as the boundary between the different soil layers. The left and the lower boundary were taken as closed flow boundaries, whereas water was able to flow through the upper and the right boundary of the model. The two dimensional finite element mesh consists of 1300 15noded elements.

In a first step, the influence of three different locations of the boundary between the upper and lower soil layer (geometries 1, 2, 3 in figure 1) was evaluated. In geometry 1 (GEO 1), the layer boundary runs through the toe of the slope, in geometry 3 (GEO 3 ) the boundary lies at the same position as the initial groundwater level and geometry 2 (GEO 3) lies exactly between them. Figure 2 shows the geometry of the slope for the case, when a highly permeable sandy layer is situated between the upper and the lower soil layer. The groundwater table was located at the boundary between the middle and the lower soil layer. All the other model characteristics were kept the same as in the "2-layered model" (Figure 1).

The initial saturation - profiles through the slope are given by the groundwater level and the chosen SWCC. Figure 3 illustrates the initial saturation profiles for the configuration "sand-silt" and "silt-sand" for geometry 1 of the two-layered model.

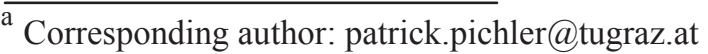




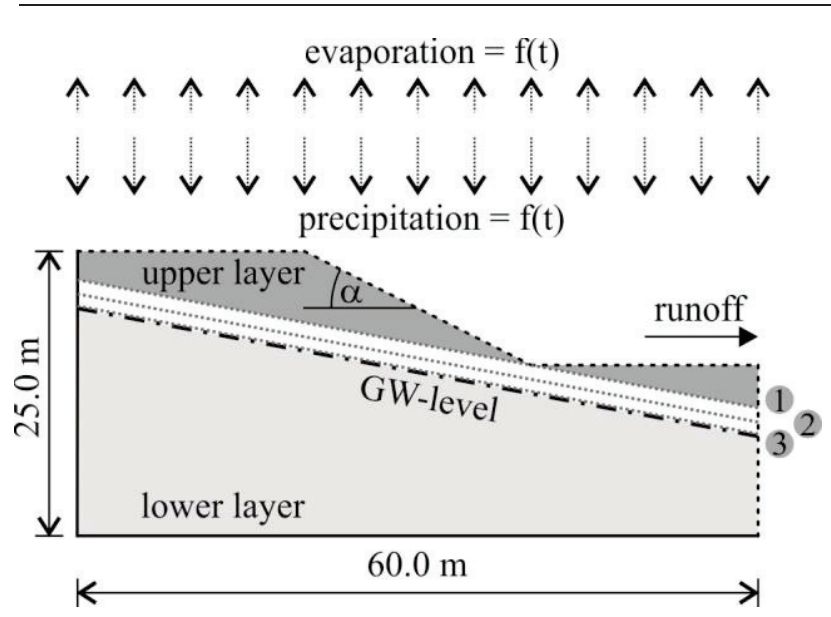

Figure 1. Geometries of the slope with two different soil layers
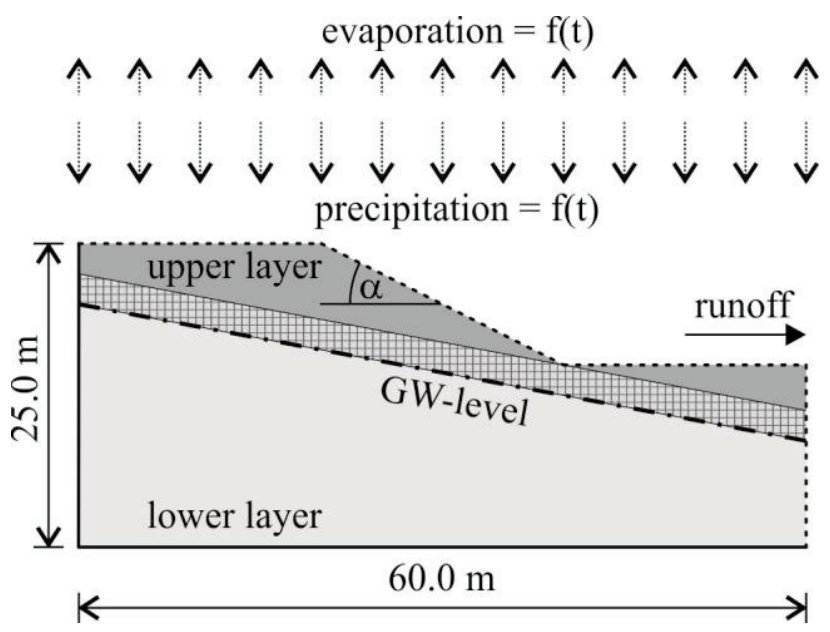

Figure 2. Geometry of the slope with three different soil layers

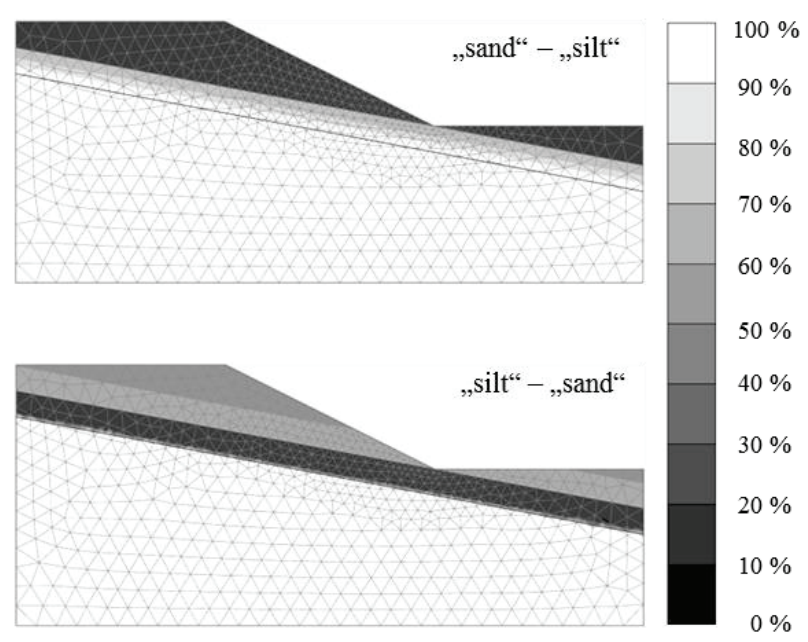

Figure 3. Initial saturation profile for the configurations "sandsilt" and "silt-sand" (GEO 1, two-layered model)

\subsection{Soil properties}

As the purpose of this study is to evaluate the influence of hydraulic properties and rainfall intensity on the FoS of the slope, the strength and stiffness parameters are assumed to be the same for all soil layers (see Table 1). Only the hydraulic properties differ for the various layers.
Table 1. Soil parameters for Mohr-Coloumb model

\begin{tabular}{c|c|c|c} 
Description & Symbol & Value & Unit \\
\hline Unit weight & $\gamma$ & {$\left[\mathrm{kN} / \mathrm{m}^{3}\right]$} & 20 \\
\hline Elasticity modulus & $\mathrm{E}^{\prime}$ & {$[\mathrm{kPa}]$} & 7500 \\
\hline Effective poissons' ratio & $v^{\prime}$ & {$[-]$} & 0.35 \\
\hline Effective cohesion & $\mathrm{c}^{\prime}$ & {$[\mathrm{kPa}]$} & 10 \\
\hline Effective friction angle & $\varphi^{\prime}$ & {$\left[{ }^{\circ}\right]$} & 20
\end{tabular}

In this study, two alternative hydraulic cases, one with a higher permeable upper layer and a less permeable lower layer and vice versa, have been investigated. The van Genuchten parameters used in this numerical analysis were taken from the USDA-Database, which is an international soil classification system [3]. The sand layer has a saturated hydraulic conductivity of $8.25^{*} 10^{-5} \mathrm{~m} / \mathrm{s}$, the silt layer $1 * 10^{-6} \mathrm{~m} / \mathrm{s}$, respectively. For the third soil layer (middle layer) also the SWCC for "sand" was taken, but the saturated permeability was increased to $1 * 10^{-3}$ $\mathrm{m} / \mathrm{s}$.

\subsection{Hydrological changes}

The influence of precipitation, evaporation and periods of no rainfall are analysed. Furthermore, various scenarios of applying the same amount of rain in different time periods were investigated. The rainfall intensities used in this study were adopted from the design rainfall for Graz (Austria) for 1 day with a return period of 20 years (around $120 \mathrm{~mm} /$ day) [4].

Different scenarios to apply the same amount of rainfall within 24 hours have been investigated:

- Condition 1 (CC1):

Constant precipitation during a predefined period with an infiltration discharge of $5 / 10 / 20 \mathrm{~mm} /$ hour for a duration of 24 hours.

- Condition 2 (CC2):

Alternating phases of precipitation and periods without precipitation (Figure 3 ).

Clarification: condition two means alternating periods with a duration of 3 hours with precipitation of 10 $\mathrm{mm} /$ hour and precipitation of $0 \mathrm{~mm} /$ hour (see Figure 4).

- Condition 3 (CC3):

Alternating phases of precipitation and evaporation (Figure 5).

Note: In order to quantify the differences between these climatic conditions, the sum of total applied rainfall ( $\mathrm{mm} /$ day) was kept the same.

- $\mathrm{q}=$ constant with $5 \mathrm{~mm} /$ hour for $24 \mathrm{~h}=120 \mathrm{~mm} /$ day - $\mathrm{q}=$ constant with $10 \mathrm{~mm} /$ hour for $24 \mathrm{~h}=240 \mathrm{~mm} /$ day - $\mathrm{q}=$ constant with $20 \mathrm{~mm} /$ hour for $24 \mathrm{~h}=480 \mathrm{~mm} /$ day

To keep the total amount of precipitation (Figure 4) or precipitation minus evaporation (Figure 5), independent of the hydraulic condition, equivalent daily discharges have been applied. 


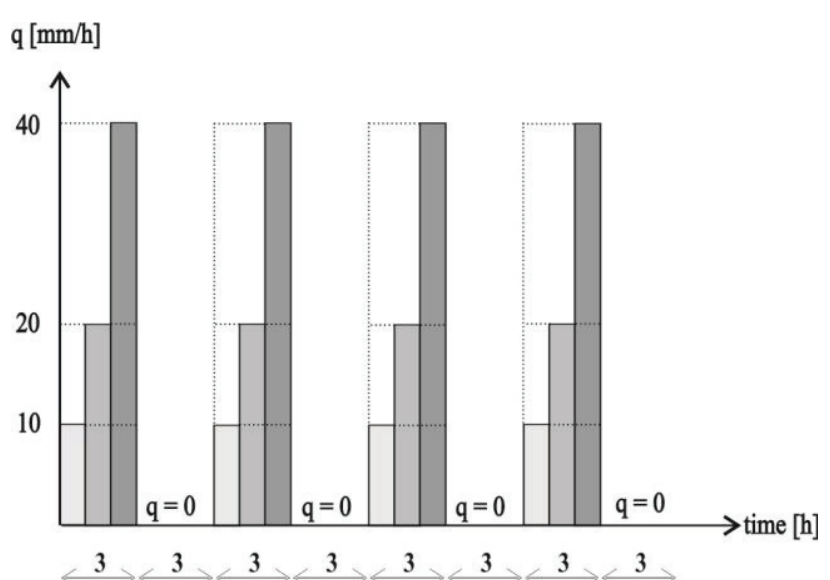

Figure 4. Condition $2(\mathrm{CC} 2)$ : Alternating phases of precipitation and periods without precipitation $(\mathrm{q}=0)$

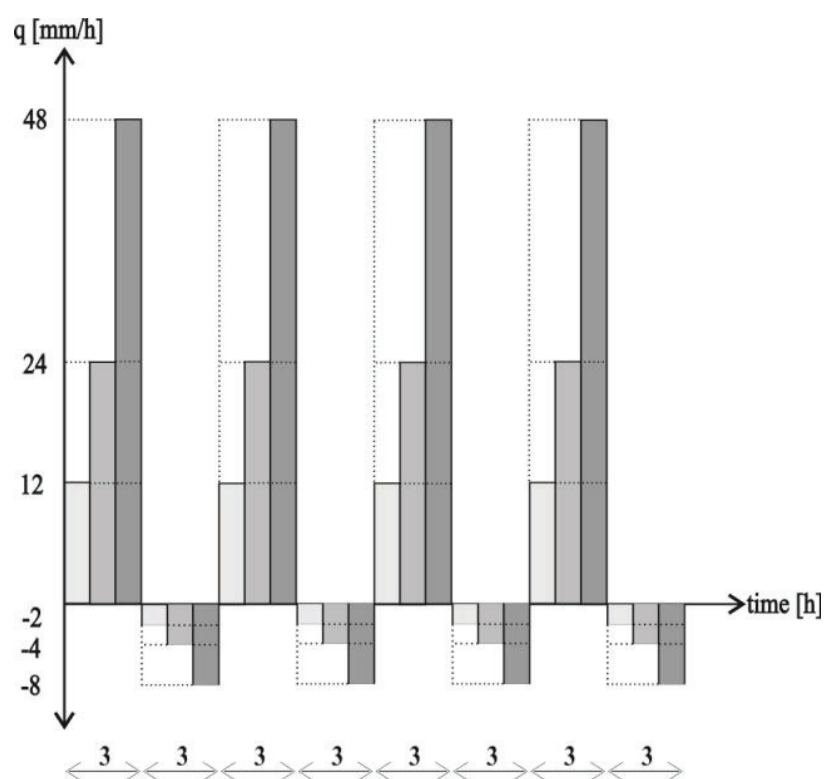

Figure 5. Condition 3 (CC3): Alternating phases of precipitation and evaporation

\section{Soil Water Retention Curve}

The hydraulic behaviour of unsaturated soils is described by the SWCC, which defines the soils capacity to keep water at different suction values. There are numerous models available to describe the SWCC mathematically, in this study the van Genuchten model was used [2].

$$
\begin{gathered}
S\left(\theta_{p}\right)=S_{\text {res }}+\left(S_{\text {sat }}-S_{\text {res }}\right)\left[1+\left(g_{a}\left|\theta_{p}\right|\right)^{g_{n}}\right]^{g_{c}} \\
\theta_{p}=\frac{p_{w}}{\rho_{w} g}
\end{gathered}
$$

The van Genuchten function (Equation 1) is a threeparameter equation which relates the saturation to the pressure head $\theta_{p}$. $S_{\text {res }}$ is defined as the residual saturation which remains even at high suction heads, $S_{\text {sat }}$ is the degree of saturation under saturated conditions, $g_{a}, g_{n}$ and $g_{c}$ are curve-fitting parameters.
Table 2. Soil parameters for Mohr-Coloumb model

\begin{tabular}{c|c|c|c|c} 
Soil & $\mathbf{k}_{\text {sat }}[\mathbf{m} / \mathbf{s}]$ & $\mathbf{g}_{\mathbf{a}}[\mathbf{1} / \mathbf{m}]$ & $\mathbf{g}_{\mathbf{n}}[-]$ & $\mathbf{g}_{\mathbf{I}}[-]$ \\
\cline { 1 - 2 } Sand & $8.3 * 10^{-5}$ & \multirow{2}{*}{14.5} & 2.68 & 0.5 \\
\cline { 1 - 2 } Sand* & $1.0 * 10^{-3}$ & & & \\
\hline Silt & $1.0 * 10^{-6}$ & 1.6 & 1.37 & 0.5 \\
\hline
\end{tabular}

Sand*: higher permeable sand layer in 3-layered model

Table 2 lists the hydraulic conductivity for saturated states and the van Genuchten curve-fitting parameters, which were used in the present study. For the "3-layeredmodel" (Figure 2) the permeability of the middle layer (Sand*) was increased to $1.0 * 10^{-3} \mathrm{~m} / \mathrm{s}$.

Figure 6 illustrates the SWCC for "sand" and "silt" (USDA, [3]).

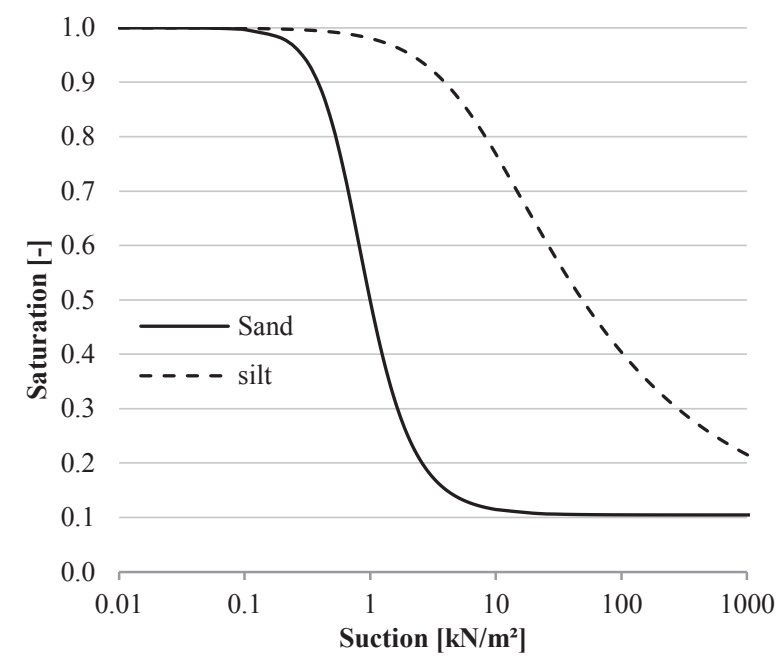

Figure 6. Soil Water Characteristic curves for sand and silt (USDA series)

\section{Relative Permeability Curve}

The coefficient of permeability in an unsaturated state depends on the saturation of the soil. The ratio of the permeability at a given saturation to the permeability in the saturated state is called relative permeability $k_{\text {rel }}(S)$. The hydraulic conductivity for unsaturated soil can be calculated by (Equation 3):

$$
\stackrel{k}{=}=k_{r e l} \underline{k}^{s a t}
$$

In order to calculate the relative permeability $k_{\text {rel }}(S)$ (Equation 5) in relation to Mualem -van Genuchten [5], the effective degree of saturation $\left(S_{e}\right)$ is obtained as:

$$
S_{e}=\frac{S-S_{r e s}}{S_{s a t}-S_{r e s}}
$$

$$
k_{r e l}(S)=\left(S_{e}\right)^{g_{l}}\left[1-\left(1-S_{e}^{\frac{g_{n}}{g_{n}-1}}\right)^{\frac{g_{n}-1}{g_{n}}}\right]^{2}
$$


Figure 7 shows the relative permeability depending on the degree of saturation for "sand" and "silt" (USDA), which were used in this study. Due to the initial depth of the groundwater level (see figures $1 \& 2$ ), the saturation of the upper soil layer is quite low. This, in combination with the chosen SWCC, led to very low values of unsaturated (relative) permeability.

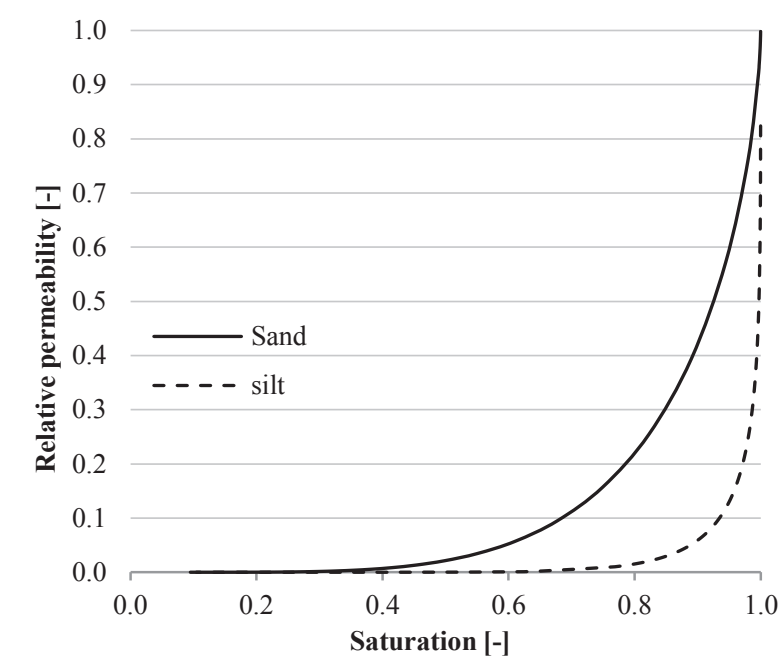

Figure 7. Relative permeability depending on saturation for sand and silt (USDA series)

In practice the permeability of a soil in situ is a parameter associated with a high degree of uncertainties. Due to that, a study with 2 orders higher permeability in the upper soil layer was done additionally (chapter 5.5).

\section{Results}

Table 3 gives an overview of the calculations which were done in this study. The influence of different geometries (GEO 1/2/3), permeability of the soil layers ("sand-silt" / "silt-sand"), hydraulic conditions (CC 1/2/3), differences between 2-layered and 3-layered models and the duration of applied rainfall events have been investigated.

To quantify the slopes' factor of safety during rainfall events after specified times of infiltration or evaporation, the well-known strength reduction method was applied (see Figure 8). The principle of the shear strength reduction technique is to reduce $c$ ' and $\tan \varphi$ ' simultaneously in small increments until failure occurs in the finite element analysis. The factor of safety (FoS), with the shear strength parameters at failure $c_{r}$ ' and $\varphi_{r}$, can be written as:

$$
F O S=\frac{\tan \varphi^{\prime}}{\tan \varphi_{r}{ }^{\prime}}=\frac{c^{\prime}}{c_{r}{ }^{\prime}}
$$

Consequently, it is possible to evaluate the effects of variations in hydraulic conditions or geometry changes on the stability of the slope.

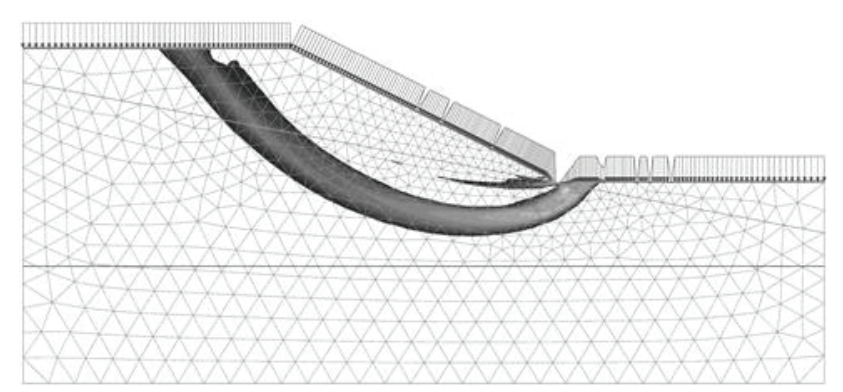

Figure 8. Incremental deviatoric strains after strength reduction method (5mm/hour, GEO1, CC1) after 24 hours

\subsection{Influence of geometry changes of the soil layers}

One major outcome of this study is that the configuration with a less permeable upper layer ("silt-sand") and climatic condition 1 , independently of geometry $(1 / 2 / 3)$, generally leads to an increase in the factor of safety. This is caused by the very low permeability of the upper soil layer.

If the applied precipitation rate is larger than the soils ability to infiltrate water, a predefined maximum head of $0.1 \mathrm{~m}$ builds up, which implicates an increase in the FoS (acts like a surcharge). Only if the predescribed maximum head $\left(\psi_{\max }\right)$ is reached, additional water is supposed to run off. This situation is certainly not realistic from a practical point of view, because runoff would probably be faster and inevitable cracks in the soil will allow water to infiltrate. However, it had been kept here in order to highlight the importance of correct boundary conditions.

In contrary, the results show a decreasing safety factor when the upper layer is more permeable ("sand-silt"). As the initial groundwater level is kept in the same location in all calculations, the initial factor of safety is given by the geometry of the model and the arrangement of the soil layers (geometry 1-3). Figure 9 shows the development of the FoS for different configurations of the geometry, whereas solely $\mathrm{CC} 1$ was applied. The differences between line types of the same kind lie within the applied total daily discharges $(120 / 240 / 480 \mathrm{~mm} /$ day $)$. It follows that the influence of geometry is more significant than rainfall events. 
Table 3. Calculations Overview

\begin{tabular}{|c|c|c|c|c|c|c|}
\hline \multicolumn{3}{|c|}{ Layer(s) } & Geometry & Duration & Total q & Climatic condition $\mathrm{CC}$ \\
\hline \multicolumn{3}{|c|}{ 2-layered model } & \multirow{2}{*}{ GEO 1} & \multirow{4}{*}{1 day } & \multirow[b]{3}{*}{$120 \mathrm{~mm}$} & \multirow{3}{*}{$\begin{array}{c}C C 1 \\
\mathrm{q}=\text { const }\end{array}$} \\
\hline Upper l & & r layer & & & & \\
\hline sand & $\mathrm{k}_{\mathrm{s}}=8.25 * 10^{-5}$ & & \multirow[t]{2}{*}{ GEO 2} & & & \\
\hline sand & $\mathrm{k}_{\mathrm{s}}=8.25 * 10^{-3}$ & S1lt & & & \multirow{2}{*}{$240 \mathrm{~mm}$} & $C C 2$ \\
\hline silt & $\mathrm{k}_{\mathrm{s}}=1.0 * 10^{-6}$ & sand & GEO 3 & \multirow{3}{*}{3 days } & & Precipitation / only flow \\
\hline Upper layer & $\begin{array}{l}\text { 3-layered model } \\
\text { Middle layer }\end{array}$ & Lower layer & \multirow{2}{*}{$1^{*}$} & & \multirow[t]{2}{*}{$480 \mathrm{~mm}$} & CC3 \\
\hline sand & sand $*\left(\mathrm{k}_{\mathrm{s}}=1 * 10^{-3}\right)$ & silt & & & & precipitation / evaporation \\
\hline
\end{tabular}

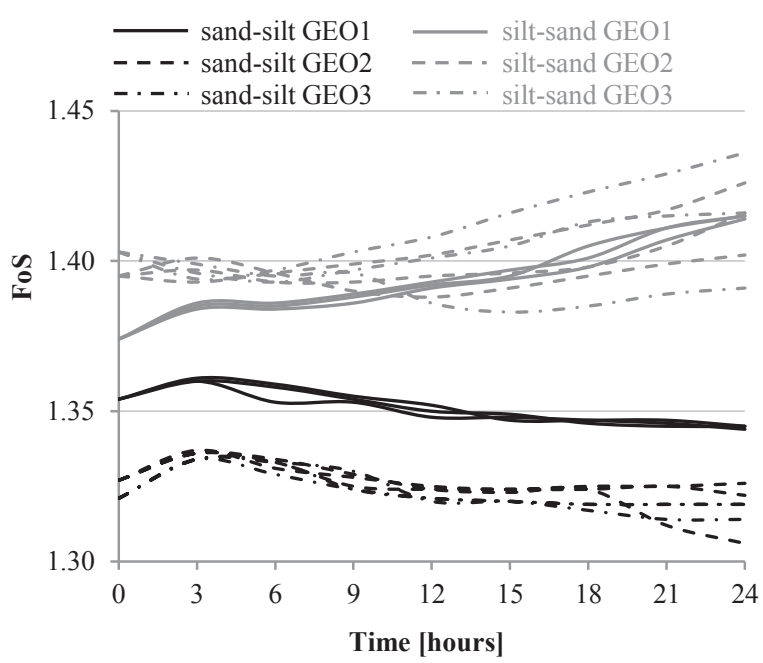

Figure 9. Development of the FoS of GEO 1/2/3 for 1 day and CC 1.

\subsection{Influence of hydraulic conditions}

Changes in the climatic conditions (CC 2/3) do not show any significant differences in the development of FoS with time compared to climatic condition 1 (CC1: constant infiltration rate over 24 hours) as described in chapter 4.1. CC2 and CC3 led to alternate periods with increasing and decreasing FoS, respectively.

In the present study, the constellation with a less permeable upper layer (silt) was no longer investigated. Due to the fact that changes in geometry (GEO 1/2/3) led to qualitatively comparable results, only GEO 1 is investigated in the following chapters.

\subsection{Comparison of 2-layered and 3-layered geometries}

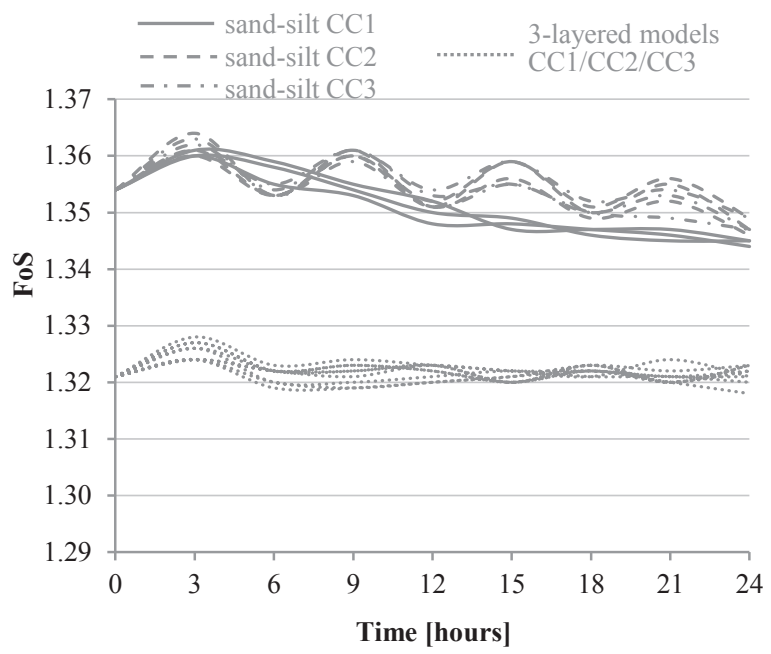

Figure 10. Development of the FoS of GEO 1 (2 layers) and the geometry with 3 layers for 1 day and CC 1/2/3.

The boundary conditions for the 3-layered soil model (figure 2) with a high-permeable soil layer between the upper and the lower layer showed negligibly small changes in the FoS with time for an observation time of 24 hours (see Figure 10).

\subsection{Development of the FoS - period of three days}

As the FoS slightly decreases when applying the total amount of rainfall within 24 hours, the influence of a three-day long lasting rainfall event (consequently with lower precipitation rates) was examined.

The results show a decrease of the FoS for the twolayered model with permeable upper layer (sand), whereas hydraulic condition 1 with a constant precipitation of $6.67 \mathrm{~mm} /$ hour for three days (equivalent to $20 \mathrm{~mm}$ / hour for 1 day) induced the largest decrease in safety with time (see Figure 11).

The investigated three-layered soil model showed again only negligible changes of the FoS with time and was therefore no longer investigated. 


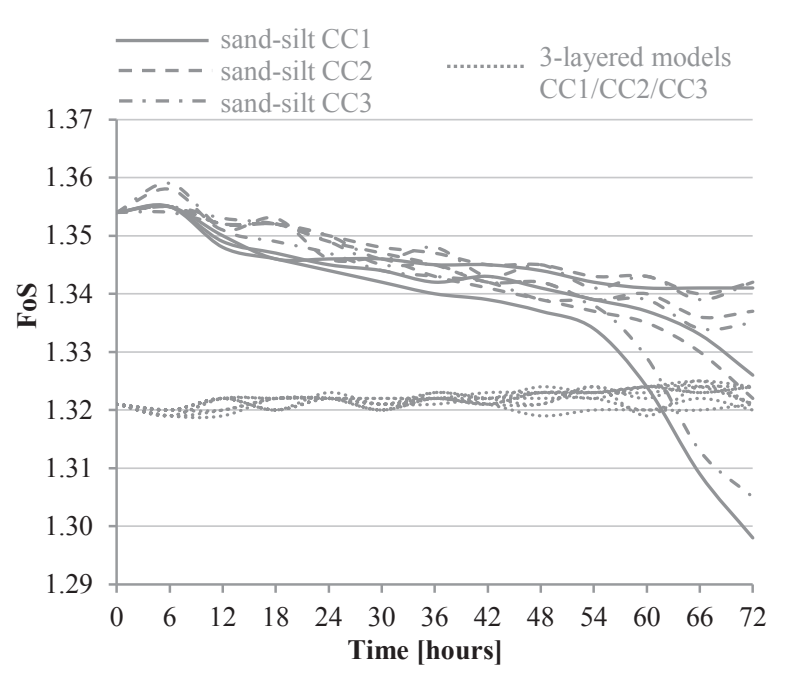

Figure 11. Development of the FoS of GEO 1 (2 layers) and the geometry with 3 layers for 3 days and CC $1 / 2 / 3$.

\subsection{Development of the FoS - period of three days and higher hydraulic permeability of the upper soil layer}

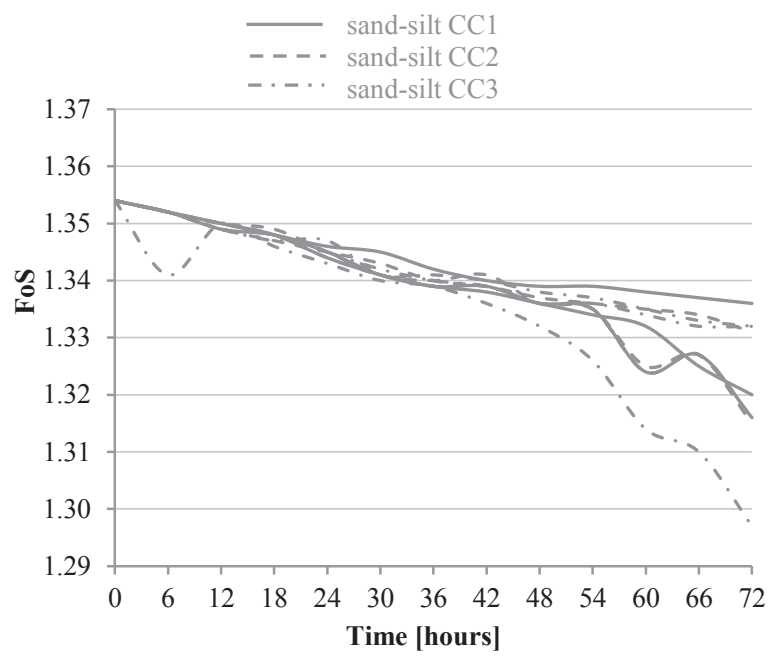

Figure 12. Development of the FoS of GEO 1 (2 layers) for 3 days, CC $1 / 2 / 3$ and 2 orders higher hydraulic conductivity of the upper soil layer.

Figure 12 shows the development of the FoS of twolayered geometries under different climatic conditions (CC 1/2/3) and two orders higher hydraulic conductivity of the upper soil layer.

The main difference, compared to the results presented in chapter 4.4 , is that there is, due to higher initial permeability, no increase in the factor of safety within the first period of precipitation (6 hours). The total decrease in the FoS after 72 hours is very small and comparable to those with lower initial permeability (compare figures $11 \& 12$ ).

\section{Conclusion}

In the present study, the changes in FoS of inhomogeneous soil slopes, which were subjected to different scenarios of rainfall, were investigated.

For the investigated boundary conditions, there are no significant differences in changes of the factor of safety between the geometries (GEO 1/2/3), which define the boundary between the two soil layers. The lower saturated permeability of fine-grained soils led to an increase in the FoS if they were taken as the upper soil layer, because a head, which acts like a surcharge, is built up. This is a situation which is unlikely to occur in practice but highlights the importance of careful selection of hydraulic boundary conditions.

Contrary to that, the factor of safety decreases if the upper soil layer has a higher saturated hydraulic conductivity, because water is able to infiltrate more easily.

There are only slight differences between the three conditions used in this study. The highest decrease in slopes' safety was generally reached under climatic condition 1, when a constant value of precipitation, without any periods of evaporation, was applied. The total sum of applied precipitation was always kept the same $\left(120 / 240 / 480 \mathrm{~mm} / \mathrm{m}^{2}\right)$ and either applied within one or three days. Compared to a one day precipitation period with higher precipitation rates where only slight changes in the factor of safety occurred, the lower precipitation rate in the case of a 3 days period led to a decrease in the FoS with time.

The results also show, that under the given boundary conditions in this study, an increase of the upper soils' layer hydraulic conductivity does not change the FoS of the slope. Further studies using different SWCC are currently under way.

\section{References}

1. H. Rahardjo, T.H. Ong, R.B. Rezaur, E.C. Leong, J. geotech. Geoenviron. Eng, 12 (2007)

2. L.L. Zhang, J. Zhang, L.M. Zhang, W.H. Tang, P I Civil Eng-Geotec, 164, Issue GE5, 299-316 (2011)

3. R.B.J. Brinkgreve, S. Kumarswamy, W.M. Swolfs, Plaxis 2D 2015 - Reference Manual, Plaxis bv, Delft, Netherlands (2015)

4. BMLFUW, Hydrografisches Jahrbuch in Österreich, 120, Gitterpunkt 5214 (2012)

5. M.T. Van Genuchten, Soil Sci. Soc. Am. J., 44, 892898 (1980). 